\title{
$\mathrm{PH} \mathbf{8 8}$ ranorama
}

\section{El museo y los derechos de autor en Europa: una encuesta y unas recomendaciones}

\begin{abstract}
¿Cómo pueden las instituciones europeas dedicadas al patrimonio cutural ofrecer el mejor acceso a sus colecciones en la era digital cuando la legislación sobre los derechos de propiedad intelectual ni está clara ni cuenta de un enfoque comunitario de base? La Red de Organizaciones de Museos Europeos (NEMO), como representante de más de treinta mil socios, ha realizado una encuesta entre las distintas instituciones europeas que servirá para estudiar el impacto de la regulación del copyright y los derechos de autor sobre el funcionamiento de los propios museos, especialmente en lo referente a las nuevas tecnologías y a las prácticas contemporáneas en Internet. NEMO pretende mostrar las dudas, cuestiones y problemas cotidianos en relación con estos temas. Aquí adelantamos los primeros resultados de este trabajo.
\end{abstract}

Julia Pagel | Secretaria General NEMO (Traducción: Victoria Frensel)

URL de la contribución <www.iaph.es/revistaph/index.php/revistaph/article/view/3684>

Hemos llegado más allá de la revolución digital. Nuestra realidad es "digital". Sin embargo, las organizaciones de patrimonio cultural se enfrentan a muchos problemas cuando intentan hacer accesibles sus bienes al público en un mundo digital. Uno de los obstáculos -probablemente el principal- es que hay que aclarar el estatus de los derechos de autor y los costes para hacer uso del patrimonio cultural.

Actualmente, con la situación en Europa, la legislación sobre los derechos de propiedad intelectual no está clara y difiere de un estado a otro y las instituciones de patrimonio tienen dificultades para cumplir su misión de dar al público el máximo acceso a sus colecciones. ¿Por qué? Porque requiere muchos recursos: humanos, económicos, de tiempo y de conocimientos. $Y$ a veces es simplemente imposible, sobre todo cuando la autoría no está clara o los bienes son más antiguos - ¿quién pensaría en determinar los derechos de autor para el uso digital antes de la revolución digital? Si no se toman medidas pronto, una parte esencial del patrimonio cultural se quedará invisible e inaccesible en el mundo (digital).

\section{¿Cómo aborda Europa los derechos de autor?}

En estos tiempos, los gobiernos de Europa están repensando su enfoque de los derechos de propiedad intelectual. A nivel nacional y de la UE se está a punto de reajustar los marcos. La Comisión Juncker está preparando la Estrategia para el Mercado Único Digital, incluyendo una revisión del marco legal de los derechos de autor, lo cual se pondrá en marcha a finales de 2015.

En este proceso es esencial incluir a todas las partes interesadas en el diálogo acerca de este tema. Esto significa que se debería involucrar junto a la industria de los derechos de autor también a otras partes interesadas, por ejemplo instituciones de patrimonio como los

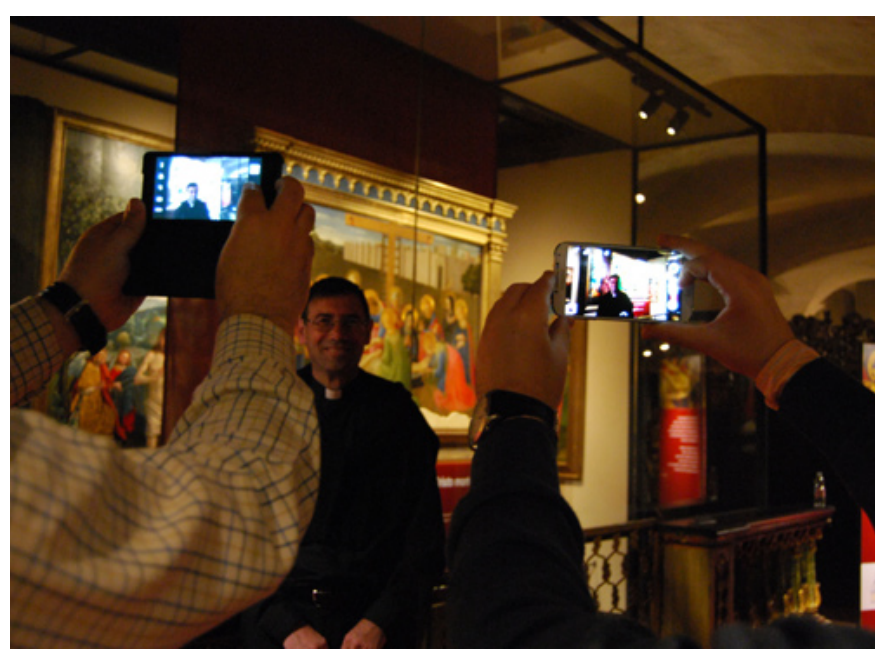

Lamentación sobre Cristo muerto de Fra Angélico. Exposición temporal de museo Diocesano de Turín (abril-junio de 2015) | foto redaccion IAPH 
museos, para trabajar en pro de un marco equilibrado del copyright en Europa.

Los museos exhiben los recursos que sostienen y atienden la educación, la formación e investigación, ellos conservan y exponen nuestro patrimonio cultural en común y dan sentido a la gente y a su identidad cultural. Pero estos mismos recursos son también la base para el empresariado creativo, para maximizar creatividad e innovación incentivando la economía creativa de Europa.

\section{Los museos y los derechos de autor}

El funcionamiento y las tareas básicas de un museo están relacionados con los derechos de autor de distintas maneras, sobre todo porque los empleados de los museos llevan a cabo muchas actividades a las que son aplicables los derechos de propiedad intelectual (por ejemplo, la redacción de un catálogo de una exposición, la publicación en Internet de un catálogo de una colección, etc.).

Los museos hacen uso de muchos servicios que son relevantes para el copyright por parte de los proveedores (por ejemplo, la escenografía de una exposición, una licencia para una base de datos, la adquisición de una obra de arte contemporánea -los derechos de reventa-, etc.) y los museos a menudo tienen una cantidad de piezas en su colección sujetas a los derechos de autor. Otro aspecto importante para los museos es la diferenciación entre los derechos de autor que sostienen los autores de las obras y aquellos que están relacionados con la copia (digital) de la obra (realizado por el fotógrafo) con la intención de hacer ésta accesible al público.

\section{Una encuesta de NEMO acerca de los museos y los derechos de autor}

La Red de Organizaciones de Museos Europeos actúa como representante de la comunidad de museos en Europa, con miembros que representan a las asociaciones nacionales de museos y otras entidades parecidas en más de 36 países, integrando así más de 30.000 museos en Europa.

La red ha participado de forma continuada en debates europeos acerca de la digitalización y el acceso online

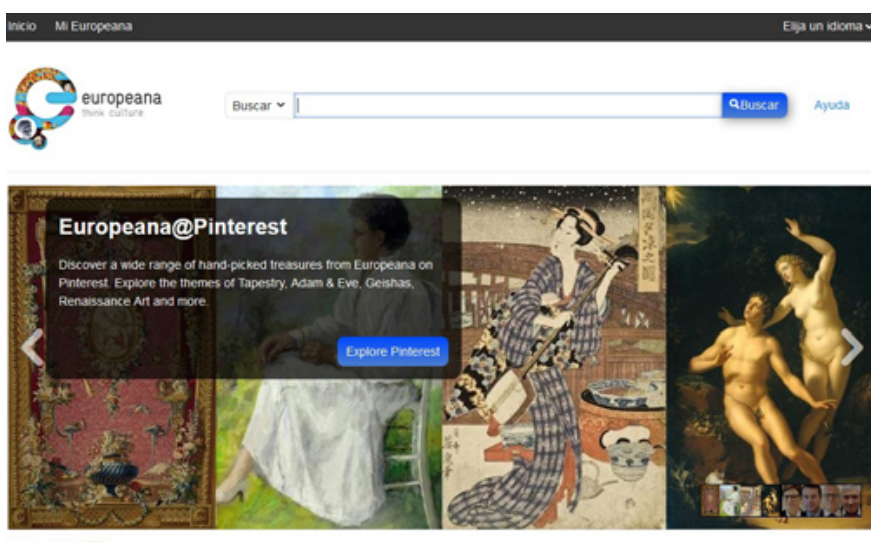

Del blog
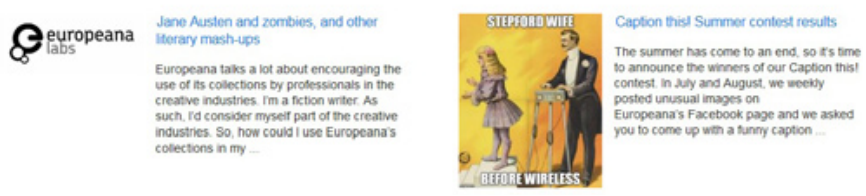

Portal de Europeana

del patrimonio cultural. Con socios como Europeana y Michael Culture, NEMO ha respondido a consultas en relación con la Directiva 2001/29/CE del Parlamento Europeo y del Consejo de 22 de mayo de 2001, relativa a la armonización de determinados aspectos de los derechos de autor y derechos afines a los derechos de autor en la sociedad de la información (Marzo 2015) ${ }^{1}$ y la Directiva 2003/98/CE relativa a la reutilización de la información del sector público (Directiva ISP, Abril 2013).

En las discusiones actuales, NEMO tiene como objetivo un acuerdo sobre los derechos de autor que permita a los museos exhibir al público lo máximo posible de su colección. Los derechos de autor son realmente complicados, siendo diferentes en cada país y requieren esfuerzos serios en cuanto al personal, administración y financiación, además ya no se adaptan a los estándares tecnológicos del siglo XXI.

Muchos museos se sienten impedidos en sus tareas y sus actividades por la legislación del copyright. Por eso, la red decidió organizar una encuesta entre los museos europeos que fue realizada por el grupo de trabajo "Intellectual Property Rights (en castellano: Derechos de Propiedad Intelectual)"2 para dar un repaso a las prácticas museísticas concretas y ejemplos de problemas en 
relación con los derechos de propiedad intelectual. Con esto, NEMO quiere ilustrar las dudas, cuestiones y problemas en torno a este tema con los que se encuentran los museos en sus actividades cotidianas. La encuesta también trataba de incluir aspectos técnicos para dar recomendaciones acerca de un funcionamiento mejor de los derechos de autor en Europa, ayudando así a los museos en el cumplimiento de su misión y sus tareas.

\section{Conclusiones de la encuesta ${ }^{3}$}

1. La necesidad de tomar conciencia sobre la influencia que ejerce la legislación de los derechos de autor en las áreas y actividades de los museos.

La encuesta de NEMO muestra que muchas de las actividades centrales de los museos están relacionadas con cuestiones de derechos de autor. Para facilitar el trabajo de los museos con el público, la legislación de los derechos de autor tiene que adaptarse mejor a las intenciones de las instituciones de patrimonio al servicio de la sociedad.

Por otro lado, los museos tienen que formarse y adquirir conocimiento sobre asuntos relevantes para museos en materia de derechos de propiedad intelectual. Los museos no siempre pueden permitirse contratar profesionales expertos externos para poder resolver problemas de esta temática.

2. Las licencias de los derechos de autor no están adaptadas a las necesidades de hoy día y a los estándares técnicos actuales; además las tarifas se perciben a menudo como excesivas.

La gestión de los derechos de autor significa costes considerables y constituye una carga burocrática para los museos. La encuesta de NEMO muestra que muchas veces las licencias no corresponden con los estándares digitales y técnicos de hoy día. Los legisladores tienen que abordar las condiciones excesivas de sociedades de gestión colectiva y de los titulares de derechos para las organizaciones que están al servicio de la sociedad.

3. Un agujero negro para el trabajo del siglo $X X$ y $X X I$, un problema causado por la legislación de los derechos de autor.
La legislación de los derechos de autor es actualmente un obstáculo enorme para la presencia de una colección de un museo en Internet. Esto se debe a los largos procedimientos que son necesarios para aclarar de quién son los derechos y a la incpacidad de pagar las licencias de estos derechos.

Para iniciativas como Google Art Institute y Europeana, que permiten la reutilización comercial, tanto las sociedades de gestión colectiva y como la de autores incrementan aún más sus tarifas o no dan licencia.

4. Ajustar los requisitos legales a la era digital y a las capacidades de los museos.

La legislación de los derechos de autor difiere de un país a otro. En general, hay poca experiencia en marcos legales (diferentes) y en el manejo del copyright por parte de los museos. Es necesario tener puntos claves de conocimiento a través de organizaciones paraguas regionales o nacionales de museos que proporcionen información relevante a los museos en caso de necesidad.

Hay que repasar la directiva de la UE sobre obras huérfanas $^{4}$ en cuanto a su viabilidad, ya que supone una fuerte carga para los museos que tienen que invertir recursos humanos y económicos para la debida búsqueda diligente de cada obra que tiene un autor desconocido.

5. Limitaciones al periodo de tiempo de derechos de autor.

En general, los museos no financian la extensión del periodo aplicable de los derechos de autor a las obras de arte porque esto provocaría más costes y recursos humanos para los museos. Algunos museos incluso piden un periodo más corto de derechos de autor.

6. Las políticas de derechos de autor de los medios de comunicación social y los museos.

Otra preocupación son las políticas de los derechos de autor de las empresas de los medios de comunicación social. La mayoría de las empresas de medios sociales reclaman el copyright para imágenes que se comparten 
en sus plataformas. Esto causa problemas con los derechos de autor existentes dentro de los museos y de los titulares de los derechos originales.

7. Las películas y los vídeos son demasiado complejos de manejar respecto a los derechos de autor.

Por lo general, los museos tienen problemas a la hora de aclarar los derechos de películas y vídeos. Esto se debe al hecho de que normalmente estos medios tienen una situación de derechos muy compleja (autores desconocidos, varios colaboradores, quién es titular de qué derecho, etc.). Hace falta una solución genérica para hacer accesible el patrimonio audiovisual a los ciudadanos.

8. A los museos les parece más fácil llegar a un acuerdo sobre los derechos de autor directamente con los autores en vez de con sus herederos o con las empresas de gestión colectiva.

El estudio muestra que a los museos les parece más fácil y menos caro llegar a un acuerdo directamente con los autores acerca de una reutilización no comercial por parte del museo. Muchas veces tanto las sociedades de gestión colectiva como los herederos de las obras del autor imponen exigencias más estrictas a sus licencias con respecto a los derechos de autor, acarreando así costes económicos, de tiempo y personal.

Para la adquisición de nuevas piezas de colección, parece razonable negociar las licencias con los autores mismos siempre y cuando se pueda. Las empresas de gestión colectiva tienen que garantizar transparencia, sobre todo en la fijación de precios, en los miembros y las licencias, y no deberían tener la capacidad de anular licencias que se hayan acordado con los propios autores.

La legislación de los derechos de autor para museos debería incluir el permiso de reutilización no comercial de forma razonable. Esto no solo incluye las áreas de educación e investigación, sino también todo tipo de tareas habituales de un museo: el registro, la exhibición pública (online), por ejemplo, las publicaciones no comerciales o las páginas web de colecciones. La demanda por una excepción open norm por parte de los museos es muy evidente.

\section{Recomendaciones}

Para conseguir un acuerdo equilibrado para todas las

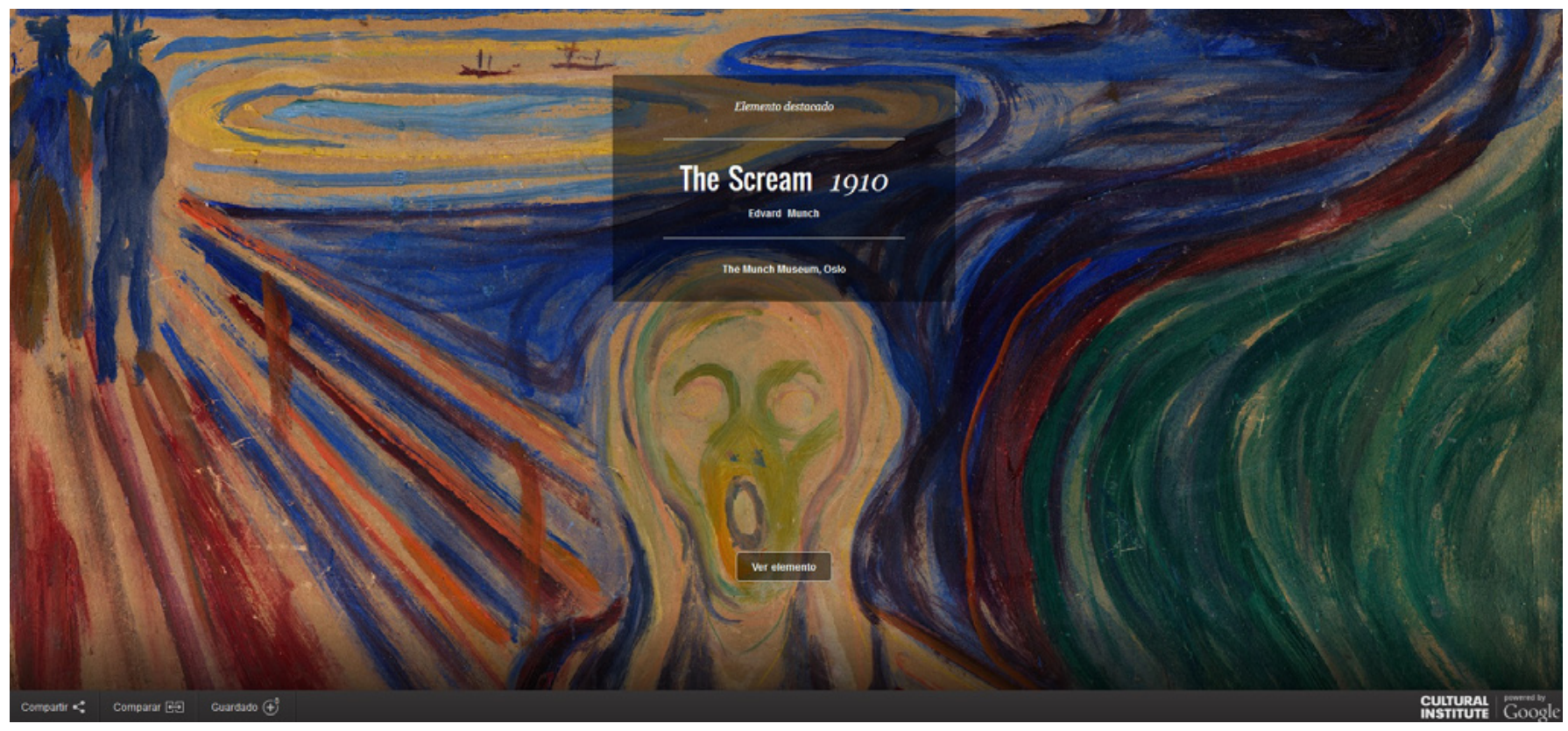

Google Art Institute. Art Project 
partes interesadas e involucradas, NEMO recomienda que:

$>$ Los museos y las instituciones de patrimonio deberían ser incluidos en el diálogo y en el trabajo acerca de las políticas en relación con cuestiones de derechos de autor.

> A los museos les debería ser posible mostrar sus colecciones online con fines educativos y de investigación.

> Se debería facilitar más recursos económicos para el desarrollo de capacidades/formación del personal para tratar con contenido digitalizado y su acceso público, incluyendo los derechos de autor.

$>$ Los derechos del autor tienen que ser simplificados para responder a la realidad y los requisitos actuales. Esto quiere decir un acuerdo armonizado europeo sobre concesión de licencias y derechos de autor. Se deberían discutir una serie de excepciones para museos como instituciones educativas al servicio de la sociedad.

> Se deberían actualizar las excepciones existentes de las que se benefician instituciones de patrimonio para posibilitar el acceso online para obras fuera de comercio que poseen estas instituciones.

$>$ Es necesario una legislación adecuada para facilitar digitalización, para posibilitar el acceso a páginas web de colecciones de museo y para estimular bases de datos de imágenes para la reutilización. Minería de datos, metadatos centrales e hipervínculos de utilidad no comercial no deberían ser objeto de licencias.

$>$ Las licencias deberían incluir generalmente un acuerdo para el uso tanto analógico como digital. Es importante diferenciar entre la reutilización para un uso comercial y no comercial.

NEMO se ofrece a participar con mucho gusto en discusiones con todas las partes interesadas, especialmente con las instituciones europeas, sobre cómo asegurar que en el futuro el patrimonio cultural europeo sea visible y accesible para la sociedad.

\section{NOTAS}

1. http://www.ne-mo.org/news/article/browse/5/nemo/ open-letter-to-the-working-group-on-intellectual-propertyrights-and-copyright-reform/356.html

2. El grupo de trabajo "Derechos de Propiedad intelectual" de NEMO es presidido por Pascal Ennaert, Colección de Arte Flamenco.

3. La encuesta completa está disponible online desde septiembre de 2015 en el sitio www.ne-mo.org

4. http://eur-lex.europa.eu/legal-content/EN/TXT/ ?uri=CELEX:32012L0028 [Consulta: 27/07/15]. 